\title{
The Mobile Holiday Seasonal Adjustment Model Research Based On the Stock Data
}

\author{
Zhihong Wang \\ Business Administration Dept. \\ Guangdong University of Finance. \\ Guangzhou, China \\ e-mail:lywzh1998@163.com
}

\author{
Qianyuan Wang \\ The Postgraduate Dept. \\ Guangdong University of Finance. \\ Guangzhou ,China
}

\begin{abstract}
Based on the shortcomings of seasonal adjustment methods of stock data, the paper takes stock data-money supply (M0) as the main research object, and designs the operation and programmed process that the explanatory variables of stock data are generated, and set up money supply (M0) model of the registration day being in at the end of the month and three zones. the money supply (M0) seasonal adjustment result shows the $Q$ statistics of the seasonal adjustment quality is 0.19 , the outliers ratio is $2.9 \%$, all the outliers appear in January and February, which shows the money supply (M0) mainly was affected by the mobile holiday- the Spring Festival in the middle of season factors, and is very small impacted by the holiday such as the Dragon Boat Festival, May Day ,emergency and the financial policy, the growth trends of month and month and year and year are almost synchronization. The paper forecasts the money supply (M0) in 2012 using the model, the average relative error of the forecast values is $2.87 \%$, which belongs to the secondary level accuracy, and is suitable for forecast of medium and long-term.
\end{abstract}

Keywords- Stock Data; X-12-ARIMA model; Money supply; Seasonal adjustment.

\section{PREFACE}

The stock data is a statistical data in a point, and the flow data is a statistical data in a period. people can adjust the flow data (such as CPI index) with different seasonal adjustment methods, but to the research about stock data is obviously insufficient, even if there are some research, people research the equal with the flow data, which kills the stock data itself characteristics. The United States census bureau thinks: "in practice, the stock data rarely need to consider seasonal factors effect, if there are seasonal factors, which can regress with the custom regression variable ", perhaps which is the main season that the research that the stock data is adjusted is lack.

In fact, the stock data also is infected by season factors in statistical process, such as China's money supply (M0), because our country people's spending habits, the people often hold more cash (namely M0) in holiday (especially the Spring Festival) in order to consume conveniently, and the less cash in peacetime. The seasonal factors will influence the statistical analysis of money supply (M0) in each period and decision and analysis of the decision-making. Research shows that the turning point of that unadjusted data reflects the economic cycle is average lag 6 months compared with the same period at the last year, and the adjusted data can be timelier reflect economic moment change and the turning point of the economic change. Therefore, in order to analyze and decide effectively and scientifically our country money supply (M0), we must strengthen the research of the stock data (such as money supply (M0)) season factor and try to reduce seasonal factors influence on money supply (M0)

The study of the money supply (M0) In our country generally uses the method to deal with the flow of data, for example, QiDongJun (2004) ${ }^{[1]}$ direct and indirect adjusts and analyzes for the China's monetary supply using X-12 -ARIMA and TRAMO/SEATS model, JiaShuMei (2005) ${ }^{[2]}$ studies money supply using X-12-ARIMA model and three section method, the method is not advisable in theory. In recent years, there are a lot of literature ${ }^{[3]-[4]}$ mention stock data adjustment method, but the operation process is not thorough, ChenXiongqiang (2011) ${ }^{[5]}$ has more detail statement in this respect, he seasonally adjusts China's monetary supply using the X-13ARIMA-SEATS model and $\wedge$ type change trend, the $\wedge$ type change shows roller-coaster change process of monetary supply, and ignores short average change in the festival period, which does not fit with the change of things development process, the analysis conclusion of M0 outliers characteristics is not convincing .

The paper uses the Genhol program thought ${ }^{[6]}$ before the festival, festival and festival after the three section influence method, and combines with the characteristics that the stock data must add into the registration day, and introduces program type the design process of explanatory variable of stock data, and design the money supply (M0) season adjustment explanatory variable accord with Chinese characteristics , and build money supply (M0) seasonal adjustment model combined with X-12-ARIMA model, which research carefully our country money supply (M0) and improve the Scientific and accuracy that the adjustment problems mobile holiday such as the Spring Festival of the money supply (M0). 


\section{MONEY SUPPLY (M0) SEASON FACTOR ANALYSIS}

According to the money supply (M0) curve characteristics, we can find that China's money supply (M0) has obvious seasonal characteristic, which is decompose specifically for the following three factors.

- Trend, cycle factors. China's money supply (M0) is gradually increasing, that is to say, currency (M0) demand is increasing in our country every year, which also shows that the our country people's consumption level is growing.

- Seasonal factors. the money supply (M0) is not smooth increasing curves, but appears periodic salient point, especially from December to February in every year, money supply (M0) has significant change, which shows the money supply (M0) is influenced by seasonal factors is bigger, but the Spring Festival appeared more from January to march in our country, therefore, we can think that mobile holiday - the Spring Festival has bigger influences for the money supply (M0), and should consider mainly mobile holiday influences for the money supply (M0).

- Irregular factors. We also can find some abnormal protuberance in the record points in the process of money supply (M0) increasing, for example, some abnormal convex point may be caused by irregular factors in 2011 year.

According to above the decomposition characteristics of the money supply (M0) factor, we can use seasonal adjustment method to adjust the season. But in the process of adjustment we must adjust the season according to the characteristics of the stock data

\section{X-12-ARIMA MODEL INTRODUCTION}

The X-12-ARIMA model that is used extensive current mainly is divided into two parts: regARIMA (the linear regression model with ARIMA time series error) and X-11 submodule. RegARIMA is used to establish ARIMA model, $\mathrm{X}-11$ is used to adjust seasonally, which is the core part of the season adjustment.

The RegARIMA uses standard ARIMA modeling method to establish the ARIMA model through the identification, evaluation and diagnosis, which is used to predict, so as to realize the continuation of the time sequence. The basic expression ${ }^{[6]}$ of the addition model is as following.

$$
\varphi(L) \phi\left(L^{s}\right)(1-L)^{d}\left(1-L^{s}\right)^{D}\left(y_{t}-\sum\left(\beta_{i} x_{i t}\right)\right)=\theta(L) \vartheta\left(L^{s}\right) a_{t}
$$

In the formula (1), $\mathrm{L}$ is for lag operator, $\mathrm{s}$ is for sea sonal cycle (monthly data $\mathrm{s}=12$, quarterly data $\mathrm{s}=4$ ), $\varphi(L)=1-\varphi_{1} L-\ldots-\varphi_{p} L^{p}$ is no season autoregr e s s i v o p e r a t o r ( A R ), $\phi\left(L^{s}\right)=1-\phi_{1} L^{s}-\ldots-\phi_{p} L^{P s}$ is seasonal regressi on operator, $\theta(L)=1-\theta_{1} L-\ldots-\theta_{q} L^{q}$ is no seas on moving average operator (MA),
$\vartheta\left(L^{s}\right)=1-\vartheta_{1} L-\ldots-\vartheta_{Q} L^{Q s}$ is the season movin $\mathrm{g}$ average operator, $\mathrm{a}_{t}$ is white noise of independent and distribution, and it's mean value is 0 , variance is $\sigma^{2}$, $(1-L)^{d}\left(1-L^{s}\right)^{D}$ shows that no season difference is $\mathrm{d}$ and seasonal difference is $\mathrm{d}\left(y_{t}-\sum_{i}\left(\beta_{i} x_{i t}\right)\right)$ is the ti me series regression error, regression variable $x_{i t}$ mainly includes four kinds of outliers (AO outliers, horizontal drift LS, temporary change TC and slash change RP) an $\mathrm{d}$ influencing factors (leap year, trading day effect and mobile holiday effect, etc.) relating to calendar. In pract ical applications, in the circumstances of statistical inde $\mathrm{x}$ being certain, the major difference of season analysis $i$ $\mathrm{s}$ the disaccord of move holiday in every country, which is also one of the important factors of influencing seaso $n$ adjustment analysis, therefore, it is an important resea rch content to use regARIMA model season adjustment that mobile holiday explanatory variable are designed a ccording to the research object..Designing Spring Festiv al effect virtual variable of money supply (M0) in our c ountry

In the process of designing China's monetary supply (M0) virtual variable, the paper references the Genhol procedure thought that is provided by C.Monsell in the United States census bureau Brian in 1998. Which is special used to generate the mobile holiday explanatory variable. The procedure divides mobile holiday effect into three kinds of effect, namely before the holiday effect, the holiday effect and after the holiday effect and its assumptions are: the economic activity level in influence period remains unchanged, and obeys uniform distribution. The procedure sets up separately three kinds of effect time length, and selects the most suitable influence aging through the final diagnosis of various inspection methods (AIC and shift interval inspection, etc.).

Combined with the current calendar and the current situation of the Spring Festival in China, On the basis of traditional practices, it is assumed that the festival influence on the money supply is not uniform distribution but $\mu$ type bimodal change, the specific design process is shown in figure 1 , the money supply is rising in the 20 days before Spring Festival, which is positively change, the money supply sharply reduced in 4 days during the Spring Festival, below the normal level, the money supply is from higher peak to gradually reduce, in the 15 days after Spring Festival, restore to the normal level. According to this classification thought, the design of virtual variable process is as follows. 


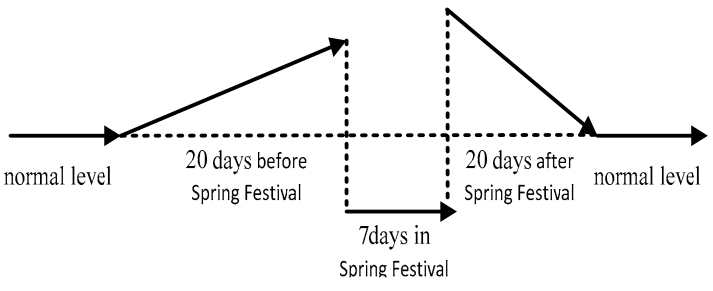

Figure 1. Figure of the Spring Festival influence on the money supply

Assuming the days that that money supply (M0) is influenced by before the Spring Festival, Spring Festival and after Spring Festival respectively is $\mathrm{Da}, \mathrm{Db}$ and Dc, according to money supply (M0) development process in the figure 1, getting influence weight is following.

$$
P_{i, j}(D)=\left\{\begin{array}{rlrl}
\frac{i}{D_{a}} & j & =1 \\
1 & j & =2 \\
\frac{n-i}{D_{c}} & j & =3
\end{array}\right.
$$

In the formula (2), $\mathrm{Pi}, \mathrm{j}$ is weight value of the $\mathrm{i}$ day. $\mathrm{j}=1$ shows before the Spring Festival, $\mathrm{j}=2$ is said the Spring Festival, $\mathrm{j}=3$ is said after the Spring Festival.

According to the characteristics of stock data, and consider the weight value of the registration day. start date (lunar New Year's day) is regarded as the division point of registration, and set length of Spring Festival, and analyze the registration day weight value of four situation of registration in the before the Spring Festival, the Spring Festival, after the Spring Festival and is not within the scope of influence. Observing the dates of the Spring Festival, and find the date is in January and February, so we need to consider the registration day weight value (that is virtual variable) of the two months in the procedure of adjusting the Spring Festival effect Seasonal. Use the way of section function, and combine with the formula (2), and get the Spring Festival effect registration day right value is such as formula (3) - (4).

The weight value that the regulation day is before division option of the Spring Festival is following:

$$
P_{1}(D)=\left\{\begin{array}{rr}
\frac{D_{a}-(s p-j a n-1)}{D_{a}} & D_{a} \geq(s p-j a n)>0 \\
1 & -D_{b}<(s p-j a n) \leq 0 \\
\frac{D_{c}+\left(j a n-s p+D_{b}\right)}{D_{c}} & -D_{b} \geq(s p-j a n) \geq-D_{c} \\
0 & \text { or } \quad(s p-j a n)<-D_{c}
\end{array}\right.
$$

In the formula (3), $\mathrm{P}_{1}$ is said the weight value when the regulation day is before division option of the Spring Festival, sp is said the data of lunar New Year's Day,jan is said the regulation day of before the Spring Festival time point, ( $\mathrm{sp-jan)} \mathrm{is} \mathrm{said} \mathrm{interval} \mathrm{days} \mathrm{of}$ the Spring Festival and the regulation day.

The weight value that the regulation day is after division option of the Spring Festival is following:

In the formula (4), $\mathrm{P}_{2}$ is said the weight value when the regulation day is after division option of the
Spring Festival, sp is said the data of lunar New Year's Day, feb is said the regulation day of after the Spring Festival time point, (feb-sp) is said interval days of the Spring Festival and the regulation day.

$$
P_{2}(D)=\left\{\begin{array}{rr}
\frac{D_{a}+\left(f e b-s p+D_{b}\right)}{D_{a}} & 0>(f e b-s p)>-D_{a} \\
1 & D_{b} \geq(f e b-s p) \geq 0 \\
\frac{D_{c}-\left(f e b-s p+D_{b}\right)}{D_{c}} & D_{b}+D_{c} \geq(f e b-s p) \geq D_{b} \\
0 & (f e b-s p)>D_{b}+D_{c} \\
& o r \quad(f e b-s p)<-D_{a}
\end{array}\right.
$$

Centered processing the weight value and constructing the explanatory variable is following:

$$
X_{i, j}(D)=P_{i, j}(D)-\overline{P_{i, j}(D)}
$$

In the formula (5), $X_{i, j}$ is said the centered processed explanatory variable of the regulation day in the $\mathrm{i}$-year and $\mathrm{j}$-month, $\mathrm{P}_{\mathrm{i}, \mathrm{j}}$ is said the regulation day weight value of in the $\mathrm{i}$-year and $\mathrm{j}$-month, $\overline{P_{i, j}(D)}$ is said average weight value in the i-year.

Join the explanation variable into formula (1) regARIMA model; if the $t$ statistic is not significant, which means the explanation variable does not have explanatory power, and get rid of it from the regression model, and reconstruct the estimation model, until get satisfactory model.

\section{MONETARY SUPPLY (M0) SEASONAL ADJUSTMENT ANALYSIS}

\section{A. Data sources and description}

Money supply (M0) data sources is from the China's wealth (http://data.caixin.com) , and choice 341 money supply (M0) data between 1984.01 and 2012.05. According to the previous analysis results, and can choose X-12- ARIMA model to season adjust the money supply (M0), in the season adjustment process, the in 1984.01-2011.12 is as a seasonal adjustment object, the data in 2012.01-2012.05 is as prediction comparison object..

\section{B. Determining the registration weights}

According to the data characteristics, the end of the each month is regarded as at the money supply (M0) registration day, namely choosing the 31 st in January, 28th in February is as time point money supply (M0) registration day before and after the Spring Festival, and divide the Spring Festival influence period into three section, namely before Spring Festival (Da), Spring Festival (Db) and after Spring Festival(Dc), the number of days respectively is 20 days, 4 days and 15 days. According to the determination method of weights introduced, using $\mathrm{R}$ language programming, and get weights on the registration day in 1984-2012 years such as table I. In table I, weights on the registration day is only listed in January and February, and don't list weights in other month. Because the Spring Festival will not appear in other month, also beyond the day 
before, the registration day won't produce the Spring Festival effect, that is, weight of the registration day is 0 .

\section{TABLE I. SPRING FESTIVAL EFFECT T WEIGHT ON THE REGISTRATION DAY}

\begin{tabular}{lllllllll}
\hline year & 1984 & 1985 & 1986 & 1987 & 1988 & 1989 & 1990 & 1991
\end{tabular}

Jan. 0.95000.05000.60001.00000.20000.75001.00000.3000

Feb.0.00000.66670.00000.00000.46670.00000.00000.3333

$\begin{array}{lllllllll}\text { year } & 1992 & 1993 & 1994 & 1995 & 1996 & 1997 & 1998 & 1999\end{array}$

Jan. 0.85000.73330.55001.00000.10000.70001.00000.2500

Feb.0.00000.00000.00000.00000.60000.00000.00000.4000

year $\begin{array}{llllllll}2000 & 2001 & 2002 & 2003 & 2004 & 2005 & 2006 & 2007\end{array}$

Jan. 0.80000.80000.45001.00000.66670.60001.00000.1500

Feb.0.00000.00000.13330.00000.00000.00000.00000.5333

\begin{tabular}{llllll}
\hline year & 2008 & 2009 & 2010 & 2011 & 2012
\end{tabular}

Jan. 0.70000.93330.35000.90000.7333

Feb.0.00000.00000.26670.00000.0000

\section{Money supply (M0) seasonal adjustment process} analysis

Use X-12-ARIMA model that the Spring Festival factors be introduced and adjust the money supply (M0) season. select registration day of the data is the end of the each month, and consider trading day effect and leap year factors in the process of the adjusting, and take natural logarithmic transformation to initial data, and select season adjustment multiplication model, it is that each decomposition factors in the sequence are mutual influence, use the Eview6.0 programming tool ${ }^{[7]}$ and X-12- ARIMA using manual ${ }^{[8]}$ and mixed program.

It is seen from the analysis results, the t statistical the constant term and leap year is respectively 1.14 and 1.8 , the $\mathrm{X} 2$ statistical of trading day is 12.21 , which are less than 0.05 significant levels, Which show that the constant term, trading day and leap year is not significant enough influence on the money supply (M0). the model measures automatically 18 and 43 outliers respectively, and 12 outliers fall on January 6 in February in eighteen outliers, it is shown that the model outliers process power is not enough, and that monetary supply (M0) has strong seasonal effect, especially in the Spring Festival season effects, and the influence of the mobile holiday such as Dragon Boat Festival, MidAutumn festival, May Day holiday and ten first-class mobile is less.

Based on the imperfection of season adjustment not considering the Spring Festival factor, introduce the Spring Festival variables in the model, and adjust money supply (M0) season. The adjustment results such as table II. The results showed that the $\mathrm{X}^{2}$ statistical of trading day is 16.08 , and the $t$ statistical of Spring Festival factors is 36.18 , which are greater than 0.05 significant levels. Which show trading day and Spring Festival factors have significant influence on money supply (M0), but t statistical of leap year is 4.58 , and not significant. The outliers detected reduce to 10 , outliers ratio is $2.9 \%$, and in the ratio range, significant levels of three (AO1985.02, TC1997.01 and AO2011.01) are strong, and are individual as a userdefined variables, money supply (M0) is more influenced by seasonal factors , and less by financial policy (financial crisis) and emergency (SARS) effect according to the interval of outliers appearing .

TABLE II. THE SEASON ADJUSTMENT RESULT CONSIDERING SPRING FESTIVAL FACTORS

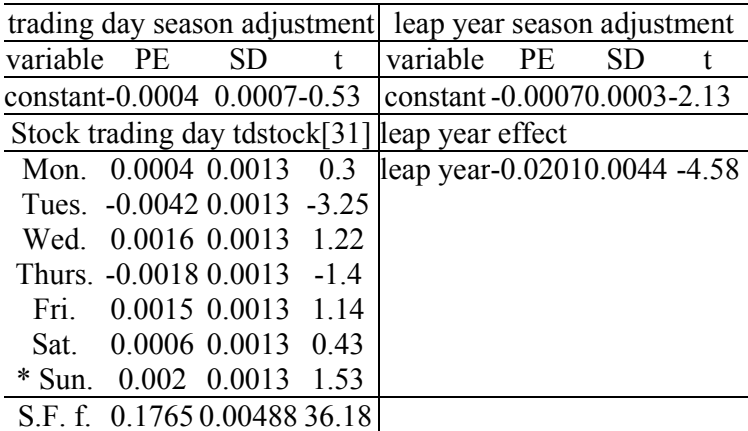

PE:parameter estimations:SD: standard deviation

Test the trend factors and irregular factors model be decomposed and F statistical of trend factor value is 287.192 , the irregular factors is 422.499 , the statistic of nonparametric Kruskal-Wallis test is 291.977, the F statistical of Spring Festival factor is 10.154, which are far greater than 0.05 significant level; according to the relative variance contribution to the money supply (M0) original sequence stability of each factor, the stability contribution(114.71) of trends - cycle factors is largest, and indicate that the money supply (M0) is steadily increase, seasonal contribution (7.61) is second, trading day and irregular factor contribution is only 0.63 and 0.03 respectively, Which show that monetary supply (M0) exists strong seasonal effect.

According to quality analysis results of the season adjustment model, 11 statistical of seasonal adjustment were $0.027,0.003,0.000,0.688,0.000,0.47,0.211$, $0.321,0.231,0.203$, and 0.186 , which is less than $1, \mathrm{Q}$ statistical of the season adjustment quality inspection is 0.19 , and is far less than 1 , which show quality of seasonal adjustment is very good.

Contrast analysis results of season adjustment curve of the original sequence, not considering the Spring Festival factors and considering the Spring Festival factors are shown in figure 2. According to the figure 2, not considering the Spring Festival factors curve has some spikes point, considering the Spring Festival factors seasonal adjustment curve is smooth a lot, and trend is very strong, which have a great significance for the money supply (M0) development, and the adjustment effect is significante. 
The seasonal adjustment model finally chosen is the most convenient, the most strong airlines modelARIMA $(0,1,1)(0,1,1)$ model, the AIC and BIC of the model respectively are 4137 and 4213 , are smaller than the AIC and BIC of not using the season of Spring Festival factor adjustment model .Use the model and forecast the money supply (M0) from January 5 months in 2012. The relative error of predictive value and the actual value is between $2 \%$ and $4 \%$, and the average relative error is $2.87 \%$, and has the very good prediction effect. The study shows that the Spring Festival effect are still significant in 2012, money supply (M0) overall trend is the increasing, monthly-on-monthly growth rate is between $8.67 \%$ and $6.19 \%$, monthly average growth is $1.12 \%$,year-on-year growth is $12.6 \%$. the monthlyon-monthly and year-on-year growth rate growth trend of monetary supply (M0) is basic synchronous, and is less by financial policy and emergency affect once again.

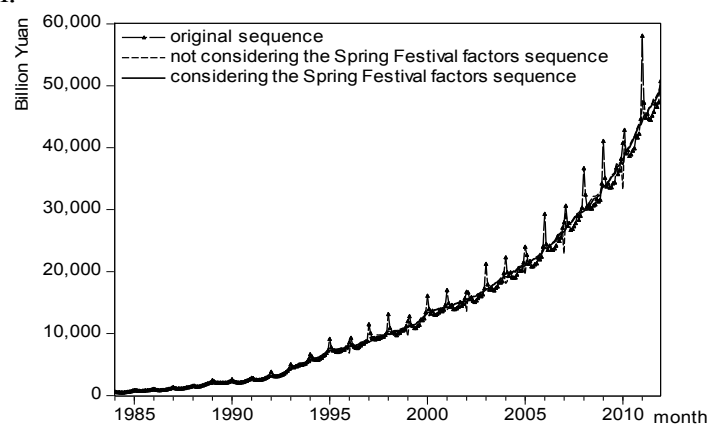

Figure 2. Comparison of Seasonal adjustment sequence and the original sequence curve

\section{MONETARY SUPPLY (M0) SEASONAL ADJUSTMENT ANALYSIS}

According to above analysis process, the conclusions are as following.

- The stock data analysis need to consider seasonal factors, money supply in China has significant seasonal. Money supply is a stock data; we pay attention to the influence of registration day, and ignore the influence of seasonal factor. In the actually, under the condition of not considering some seasonal factors, the model tests a large number of outliers, and these outliers centralized basically in January and February every year, which indicate that monetary supply seasonal effect is significantly, especially Spring Festival effect in the mobile holiday is more outstanding.

- The stock data registers day right value reckoned using curve trend change method is more scientific and reasonable. Abandon the traditional think that holiday effect change uniformly before Spring Festival, Spring Festival and after Spring Festival, and set up the development tendency that rising before Spring Festival, normal level during the Spring Festival, gradually reducing after Spring Festival, and calculate the money supply (M0) registration day weights according to the development process

- The Spring Festival is mainly season influence factors of the money supply (M0).According to the analysis results, although the trading day, leap year and some financial policy and seasonal factors has certain effect on money supply, the $t$ statistical Spring Festival factor is 36.18 , and is far bigger than statistics of other factors, which is consistent with month of outliers appearing.

- Money supply (M0) is smaller influenced by financial policy and emergency, the change trend monthly-on-monthly growth rate is mostly identical to year-on-year growth rate.

- The Spring Festival season adjustment model has well the season adjustment quality, and the model forecast precision is high. 11 season adjustment quality statistical and final Q statistical are far less than 1, which have good season adjustment effect. Outliers' number reduces from 48 to 10 .according to figure 2; season adjustment curve is smoother, which has certain guiding significance to development trend. Use the model forecast of 2012 money supply (M0) in 2012, the average relative error of prediction is $2.87 \%$, belongs to the secondary precision $^{[9]}$, which is fit to the short and medium term prediction, forecasting results can be used as reference of maker's decision.

\section{REFERENCES}

[1] QI Ya-dong. The application of seasonal adjustment method in the money supply $[\mathrm{J}]$, Quantitative \& technical economics. 2004.06:147-155.

[2] JIA Shu-mei. Empirical studies of Money supply seasonal adjustment on eliminating The Spring Festival factors $[\mathrm{J}]$, Statistical Research.2005.10:63-68.

[3] Wang Qun-yong,Wu Na. Seasonal Adjustment of China Monthly Data: A New Scheme [J]. Statistical Research.2010.27 (8):8-13.

[4] LUAN Hui-de, ZHANG Xiao- tong. A Spring Festival Model for Seasonal Adjustments [J], China Economic, 2007, 6(2):707722.

[5] Chen Xiong-qiang,Zhang Xiao-tong. Real - time Monitoring for Money Supply:Based on Seasonal adjustment Approach [J]. Shanghai Econmic Review.2011 .7:26-34

[6] The Survey Statistics of the People's Bank of China. X-12ARIMA Seasonal Adjustment-Principle and Method [M]. BeiJing:China's Financial Press, 2006: 126-127.

[7] Zhang Xiao-Tong.A Guide to Using EVIEWS [M]. BeiJing:China Machine Press.2007.146-195.

[8] U.S.Census Bureau .X-12-ARIMA Reference Manual Version 0.2.10.2002.

[9] Zhen Xiao-ping,Gao Jin-ji. Accident prediction theory and method [M]. BeiJing:Tsinghua University Press.2009:137. 